\title{
Carriage of sub-microscopic sexual and asexual Plasmodium falciparum stages in the dry season at Navrongo, Ghana
}

\author{
Geoffrey R. Atelu ${ }^{1,2}$, Nancy O. Duah ${ }^{3}$ and Michael D. Wilson ${ }^{4}$ \\ Ghana Med J 2016; 50(4): 220-227 DOI: http://dx.doi.org/10.4314/gmj.v50i4.4 \\ ${ }^{1}$ Ghana Field Epidemiology and Laboratory Training Program, School of Public Health, College of Health \\ Sciences, University of Ghana, Legon, Ghana ${ }^{2}$ Ghana Health Service, Accra, Ghana ${ }^{3}$ Epidemiology Depart- \\ ment, Noguchi Memorial Institute for Medical Research, University of Ghana, P. O. Box LG 581, Legon, \\ Ghana ${ }^{4}$ Parasitology Department, Noguchi Memorial Institute for Medical Research, University of Ghana, P. \\ O. Box LG 581, Legon, Ghana
}

Corresponding author: Dr. Nancy O. Duah

E-mail: nduah@noguchi.ug.edu.gh

Conflict of interest: None declared

\section{SUMMARY}

Background: We investigated the prevalence of sub-microscopic Plasmodium falciparum infections and gametocyte carriage in asymptomatic individuals in Navrongo in northern Ghana, an area of seasonal malaria transmission. Design: A cross sectional study of 209 randomly selected participants of all age-groups was conducted in February and March, 2015.

Methods: Capillary blood samples collected from these individuals were used for the detection of both asexual and gametocyte stage parasites by microscopy, reverse transcriptase polymerase chain reaction (RT-PCR) and conventional nested PCR methods. The prevalence data as determined by microscopy and molecular methods were compared using chi-square tests.

Results: Parasitaemia from these asymptomatic infections ranged from 40 to 3,520 parasites/ $\mu 1$ of blood (geometric mean parasitaemia $=732$ parasites $/ \mu 1)$. The prevalence of asymptomatic $P$. falciparum carriage was $4.8 \%(10 / 209)$ and 13.9\% (29/209) using microscopy and RT-PCR respectively. The overall prevalence of sub-microscopic infections in the total number of samples analysed was 9.1\% (19/209) and 66\% (19/29) of the asymptomatic infections. $P$. falciparum gametocytemia detected by microscopy was $1 \%(2 / 209)$ and $3.8 \%(8 / 209)$ by PCR.

Conclusion: This is the first report of sub-microscopic asexual and gametocytes infections in the dry season in a seasonal malaria transmission area in Ghana. It has established that persistent latent malaria infections occur and that these could supply the source of parasites for the next transmission season. The findings highlight the presence of sub-microscopic infections and therefore the need for active case detection surveillance to eliminate "asymptomatic reservoir" parasites and consequently break the transmission of the disease in Ghana.

Funding: Bill and Melinda Gates Foundation grant awarded to Noguchi Memorial Institute for Medical Research Postdoctoral and Postgraduate Training in Infectious Diseases Research (Global Health Grant \# OPP52155); National Institutes of Health grant (NIH-NIAID RO1 \# 1RO1AI099623) to MDW; European Developing Countries Clinical Trials Partnership (EDCTP)-West African Network of Excellence for Clinical Trials in TB, AIDS and Malaria (WANETAM) (Project code CB.07.41700.007).

Keywords: Plasmodium falciparum, asymptomatic infections, sub-microscopic infections, microscopy, reverse transcriptase PCR, Navrongo

\section{INTRODUCTION}

The integrated interventions against the malaria parasite and the vector have led to reduction in malaria mortality by $47 \%$ globally and $54 \%$ in WHO Africa Region during the period 2000-2013. ' Within the same period, mortality rates among under-five age group also declined by $53 \%$ globally and by $58 \%$ in Africa. As such, the new malaria agenda is focused on the elimination of the disease at country level and eradication globally through malaria treatment and vector control. ${ }^{2,3}$ Among the planned strategies to achieve elimination is to target asymptomatic infections otherwise known as the parasite 'asymptomatic reservoir' to treat and kill the para- 
sites. ${ }^{4}$ These infections can either be 'microscopic' detectable by microscopy or sub-microscopic by molecular methods only. ${ }^{5}$ Most asymptomatic infections remain untreated and thus, the possibility of transmission of the disease in the presence of vectors. The Malaria Eradication Research Agenda (malERA) therefore suggests the treatment of any level of parasitaemia because it represents a potential for transmission. ${ }^{6}$ This makes sub-microscopic infections targets for parasite elimination.

As malaria elimination programs pursue mass screening and treatment of asymptomatic individuals, further research is needed to define the degree to which submicroscopic malaria contributes to the transmission of parasites from the infectious reservoir and, in turn, what diagnostic detection threshold is needed to effectively interrupt transmission. Since parasites from asymptomatic infections persist for long periods due to lack of treatment and may develop into gametocytes which are picked up by mosquitoes for onward transmission and therefore it has become expedient to detect such infections in order to break transmission. ${ }^{7}$ Plasmodium falciparum gametocytes can be detected in the bloodstream 7 to 15 days after asexual parasites are seen. ${ }^{8,9}$ A recent study using molecular gametocyte detection tools and modelling concluded that gametocytes may persist for well beyond one month after clearance of asexual parasites. ${ }^{10}$ The ability of a few matured gametocytes from sub-microscopic infections to form gametes that will produce numerous oocytes then to infectious sporozoites therefore should not be underestimated. Studies conducted in the Gambia and Kenya have shown that about $15-20 \%$ of untreated asymptomatic infections developed into transmissible gametocytes after four weeks. ${ }^{11,12}$ Studies conducted in Ethiopia, Senegal, Colombia and Thailand revealed the prevalence of submicroscopic malaria carriage to be $19.2 \%, 14.8 \%, 9.7 \%$ and $11.4 \%$ respectively. ${ }^{13,14,15,16}$ This is indicative of the presence of such low level parasitaemia and the interest to detect these infections in malarious areas for the purpose of elimination.

In 2012, Ghana recorded an estimated 6.9 million cases of malaria out of which 17,000 deaths occurred. ${ }^{17}$ In this era where all efforts are geared towards malaria elimination, data on malaria transmission potential of asymptomatic malaria infections is most appropriate. The determination of the prevalence of sub-microscopic infections and the relative contribution to the overall transmission of malaria in the country will provide significant information that will be useful towards the elimination efforts.
The northern parts of Ghana experience seasonal malaria transmission with high transmission during the rainy season followed by comparatively low to no transmission during the dry season spanning five months. ${ }^{18}$ However, upon the onset of the rains, there is an upsurge of malaria cases at the Out Patient's Departments (OPDs) in health centres, clinics and hospitals, which is suggestive of the persistence of parasites throughout the dry season. ${ }^{18}$ The seasonal malaria transmission areas can be used as sites to begin the elimination efforts by finding and treating the asymptomatic reservoir just before the transmission season. This study therefore determined the prevalence of sub-microscopic P. falciparum parasite infections and gametocyte carriage in asymptomatic individuals in northern Ghana to provide scientific evidence-based data on such infections. This study is the first to describe the prevalence of submicroscopic infections in this part of Ghana.

\section{METHODS}

\section{Study Site}

The study was carried out in Navrongo, the administrative capital of Kassena-Nankana District (KND) in the Upper East Region of Ghana. Navrongo has an estimated population of 25,470 and lies in Guinea savanna zone with distinct wet and dry seasons. The wet season extends from April to October and the dry season starts from November and ends in the latter part of March. The entomological inoculation rate in the dry season is about 10 infective bites per person per month whilst for the wet season is about 50 infective bites per person per month. ${ }^{18}$ The population consists of two distinct ethnic groups, the Kassena forming $49 \%$ of the district's population and the Nankani about 46\%. The Builsa and migrants make up the remaining 5\%. The inhabitants live within traditional compounds of extended family groups. The site is served by the Navrongo Health Research Centre (NHRC), which uses the Navrongo Health and Demographic Surveillance System (NHDSS), a computerized database, to track births, deaths, migration and other population features. Fieldworkers visit compounds every three months to collect data on their health and socio-demographic information. ${ }^{19}$ Malaria is endemic in the area and is the most important cause of morbidity and mortality in KND. ${ }^{18} P$ falciparum is the predominant parasite species, being transmitted in the area by both An. gambiae s.s. and An. Funestus. $^{20}$

\section{Study Design}

A cross sectional study was conducted during the months of February and March 2015, a period of low to zero malaria transmission in the northern part of Ghana. 


\section{Inclusion criteria}

Males and females of all ages living in the communities of Navrongo who showed no signs and symptoms of malaria (which include, absence of axillary temperature $\geq 37.5^{\circ} \mathrm{C}$ or history of fever during the past 24 hours, headache and vomiting) were eligible for the study. In addition to the ability to give informed consent either by self or parent/guardian, they were recruited for the study.

\section{Exclusion criterion}

Neonates were excluded since they are less than 4 weeks old and may not carry parasites due to the low transmission season.

\section{Sample size determination}

The sample size determination was based on achieving a $90 \%$ power of detecting sub-microscopic malaria parasite carriers, with $95 \%$ confidence that the sample proportions obtained will differ from the population proportions by not more than $5 \%$. Using an estimated submicroscopic malaria prevalence of $15 \%$, a mean value from previous studies sample size (n) of 196 participants was determined. ${ }^{15}$

\section{Sampling}

Stratified random sampling method was employed in selecting the study participants. The total population of Navrongo central was categorized into six age groups, $<5,5-14,15-24,25-34,35-44$ and $>44$ years using the database of the Navrongo Health Demographic Surveillance Health System (NHDSS). Forty-four individuals were then selected randomly per age group by a computerized system. This number was selected to make room for absenteeism and non-consenting persons as well as those who may not meet the inclusion criteria. A list of the selected individuals with household and compound identification numbers was generated. All the selected compounds were visited and those who consented after meeting the inclusion criteria were recruited.

\section{Ethics}

All participants were given detailed information about the study aim and procedures in both English and the local language before they signed or thumb printed individual consent forms. Parents and guardians signed or thumb-printed on behalf of their children below 12 years, while assent forms were signed or thumb-printed by children between 12 and 17 years. Participants were assured of their privacy and confidentiality by allocating codes/numbers to samples instead of their names Individual informed consent was obtained after the consent form was read and interpreted to them in the local language. Ethical approvals for this study were obtained from Institutional Review Boards of the Noguchi Memorial Institute for Medical Research (NMIMR IRB CPN 043/14-15) and the Navrongo Health Research Centre (NHRCIRB195).

\section{Data Collection}

\section{Questionnaire Data Collection}

Information on demographic characteristics of each participant was collected by means of a structured questionnaire.

\section{Detection of malaria parasites by microscopy}

Thick and thin blood films were prepared on the same slide with blood (total of 9ul; 6ul for thick film and 3ul for thin film) from a finger prick from each participant. The blood smears prepared from the field were air dried, the thin films fixed with absolute methanol and both stained with $10 \%$ Giemsa stain for 10 mins. The stained slides were examined at two different laboratories by experienced microscopists. A slide was considered negative only after 200 oil emersion fields have been examined without seeing a parasite. Any discordant result was again assessed by a third microscopist before the final result was recorded. Parasitaemia was determined by counting the number of asexual parasites per 200 white blood cells and converted to per microliter $(\mu l)$ by assuming a white blood cell count of 8000 cells per $\mu 1$. The sexual parasite count was done per 1000 white blood cells.

\section{Detection of Plasmodium sp. using reverse transcription} polymerase chain reaction ( $R T-P C R$ )

About $250 \mu 1$ of blood was taken into EDTA tube using the finger-prick method and $750 \mu 1$ of Trizol reagent (Life Technologies, USA) was added on ice, and the mixture stored at $-80^{\circ} \mathrm{C}$ in the laboratory, until samples were transported under cool condition to Accra for molecular analysis. High quality RNA was extracted from the whole blood preserved in Trizol using the manufacturer's protocol (Life Technologies, USA). Plasmodium parasites detection used the RNA samples following a published protocol for genus-specific RT-PCR. ${ }^{21}$ Briefly, an initial step involved the cleaning of the RNA template by removing contaminants such as genomic DNA using QuantiTect Reverse Transcription Kit (Qiagen, Hilden, Germany). Then the reverse-transcription (RT) reaction was done for the generation of cDNA. The cDNA of all the samples were then used for the RT-PCR detection of Plasmodium species. Amplification and real-time measurements were performed in the Applied Biosystems 7300 analytical PCR system (Life Technologies, USA). The reaction mix of $9 \mu 1$ contained $0.4 \mu \mathrm{M}$ each primer, $0.2 \mu \mathrm{M}$ probe, and $4 \mathrm{mM} \mathrm{MgCl}_{2}$, QuantiTect Probe RT-PCR Master Mix (Qiagen, Hilden, Germany) and QuantiTect RT Mix (a blend of 
Omniscript and Sensiscript Reverse enzymes) as recommended by the manufacturer at a rate of $1 \mu 1$ per 100 $\mu 1$ of the reaction master mix. A volume of $1 \mu 1$ of template was added to the mix. The cycling parameters were $50^{\circ} \mathrm{C}$ for $30 \mathrm{~min}$ for reverse transcription, $95^{\circ} \mathrm{C}$ for $10 \mathrm{~min}$ and 40 cycles of $95^{\circ} \mathrm{C}$ for 15 seconds, $60^{\circ} \mathrm{C}$ for 1 minute.

Detection of P. falciparum gametocyte by nested RTPCR

The gametocyte $P f_{S} 25$ transcript was detected using nested RT-PCR following published protocols. ${ }^{22,23}$ Briefly, the cDNA generated from the reverse transcription reaction described above was used for the nested PCR. The primary PCR was conducted by adding $2 \mu 1$ of cDNA from the RT step to $23 \mu 1$ of master mix that contained; $100 \mu \mathrm{M}$ of each dNTP, 1X PCR buffer $(50 \mathrm{Mm}$ $\mathrm{KCl}, 20 \mathrm{mM}$ Tris-HCl, $\mathrm{pH} 8.3$ ), $1.5 \mathrm{mM} \mathrm{MgCl}_{2}, 1.25 \mathrm{U}$ of Taq polymerase enzyme and $0.4 \mu \mathrm{M}$ of a set of primers, F1: 5'-TAA TGC GAA AGT TAC CGT GG-3' and R1: 5'-TCC ATC AAC AGC TTT ACA GG-3'. The cycling conditions were an initial denaturation at $94^{\circ} \mathrm{C}$ for 2 minutes, 45 cycles of $94^{\circ} \mathrm{C}$ for 30 seconds, $52^{\circ} \mathrm{C}$ for 60 seconds and $68^{\circ} \mathrm{C}$ for $2 \mathrm{~min} 30$ seconds. Two microliters of the amplicon was used for the nested PCR using the primers, F2: 5' - AAC CAT GTG GAG ATT TTT CC3' and R2: 5'- ACA TTC TTA CAT TCA TTT GG-3'. The cycling conditions were the same as for the primary PCR, but for 30 cycles instead. The expected size of the PCR product was $124 \mathrm{bp}$ for $P$. falciparum gametocytes.

Detection of Plasmodium species using nested PCR

The samples positive by the genus assay were further analysed for Plasmodium species using conventional PCR on parasite DNA extracted from whole blood using published protocols with few modifications. ${ }^{24,25}$ Briefly, the reactions were carried out in final volume of $25 \mu$, which contained 1X PCR buffer, $4 \mathrm{mM} \mathrm{Mgcl} 2,200 \mu \mathrm{M}$ of each dNTP, $0.25 \mu \mathrm{M}$ of each primer, $1 \mathrm{U}$ of Taq polymerase and $2 \mu 1$ of genomic DNA for the primary amplification. The nested reaction was carried out with similar reaction mix except that $1 \mu 1$ of the primary PCR products was used as template. The cycling conditions for the primary reaction were an initial denaturation at $94^{\circ} \mathrm{C}$ for 1 minute, 35 cycles of $94^{\circ} \mathrm{C}$ for 1 minute, $58^{\circ} \mathrm{C}$ for 2 minutes and $72^{\circ} \mathrm{C}$ for $5 \mathrm{mins}$, and a final extension at $72^{\circ} \mathrm{C}$ for 5 minutes. The nested reaction was carried out with the same parameters but was 30 cycles instead of the 35 cycles. The expected size of the PCR amplified fragments for $P$. falciparum is $205 \mathrm{bp}$.

\section{Data Analysis}

The results were entered into Epi-data 3.0 and exported to StataMP11 software (Stata Corporation, College Station, USA) for analysis. Univariate analysis was carried out to determine frequencies and proportions. Baseline characteristics were cross tabulated to determine the prevalence of asymptomatic infections for both microscopic and sub-microscopic parasitaemia and these were compared using chi-square tests. Chi-square test for trends was used to determine increasing or decreasing trends in detected parasitemia with age using GraphPad Prism version 5.01 (GraphPad Software Incorporated, California, USA)

\section{RESULTS}

A total of 209 individuals participated in the study and comprised of $98(46.9 \%)$ males and $111(53.1 \%)$ females. The mean age plus standard deviation was $27.9 \pm$ 21.02 years and the age range was 1 to 82 years. Of the 209 participants, 162 (77.5\%), 18 (8.6\%), $3(1.4 \%)$ and 26 (12.4) were of the Kassena, Nankam, Builsa tribes and migrant residents in Navrongo respectively. Investigation on ITN use revealed poor patronage and only $12.4 \%(26 / 209)$ of the participants used them regularly. There was no significant difference between those who sleep under nets $(15.4 ; 4 / 26)$ and those who do not $(13.6 ; 25 / 183)(\mathrm{p}>0.05)$.

Table 1 Characteristics of the study population and parasite prevalence

\begin{tabular}{|c|c|c|c|}
\hline $\begin{array}{l}\text { Characteristics } \\
\text { (209) }\end{array}$ & $\begin{array}{l}\text { Number } \\
\text { Examined } \\
\text { n (\%) }\end{array}$ & $\begin{array}{l}\text { Prevalence by } \\
\text { Microcopy } \\
\text { n (\%) }\end{array}$ & $\begin{array}{l}\text { Prevalence by PCR } \\
\text { n (\%) }\end{array}$ \\
\hline \multicolumn{4}{|l|}{ Age groups(years) } \\
\hline$<5$ & $29(13.9)$ & $3(10.3)$ & $4(13.7)$ \\
\hline $5-14$ & $38(18.2)$ & $2(5.3)$ & $8(21.1)$ \\
\hline $15-24$ & $37(17.7)$ & $1(2.7)$ & $8(21.6)$ \\
\hline $25-34$ & $34(16.3)$ & $1(2.9)$ & $3(8.8)$ \\
\hline $35-44$ & $31(14.8)$ & $2(6.4)$ & $4(12.9)$ \\
\hline$>44$ & $40(19.1)$ & $1(2.5)$ & $2(5.0)$ \\
\hline \multicolumn{4}{|c|}{$\begin{array}{l}\text { Malaria treatment in } \\
\text { the past } 2 \text { weeks }\end{array}$} \\
\hline Treated & $5(2.4)$ & $0(0)$ & $0(0)$ \\
\hline Not treated & $204(97.6)$ & $10(4.9)$ & $29(14.2)$ \\
\hline \multicolumn{4}{|l|}{ ITN use } \\
\hline Use net & $26(12.4)$ & $2(7.7)$ & $4(15.4)$ \\
\hline Does not use net & $183(87.6)$ & $8(4.4)$ & $25(13.7$ \\
\hline \multicolumn{4}{|l|}{ Occupation } \\
\hline Farmer & $18(8.6)$ & $2(11.1)$ & $2(11.1)$ \\
\hline Public Servant & $8(8)$ & $0(0)$ & $0(0)$ \\
\hline Trader & $64(30.6)$ & $2(3.1)$ & $6(9.4)$ \\
\hline Unemployed & $119(56.9)$ & $6(5.0)$ & $21(17.6)$ \\
\hline \multicolumn{4}{|l|}{ Level of education } \\
\hline No formal Education & $53(25.4)$ & $5(9.5)$ & $19(18.1)$ \\
\hline Basic Education & $105(50.2)$ & $4(3.8)$ & $2(5.9)$ \\
\hline Senior High & $34(16.3)$ & $1(2.9)$ & $1(5.9)$ \\
\hline Tertiary & $17(8.1)$ & $0(0)$ & $7(13.2)$ \\
\hline \multicolumn{4}{|l|}{ Marital status } \\
\hline Married & $98(46.9)$ & $2(2.0)$ & $4(4.1)$ \\
\hline Single & $103(49.3)$ & $8(7.8)$ & $23(22.3)$ \\
\hline Divorced & $8(3.8)$ & $0(0)$ & $2(25.0)$ \\
\hline
\end{tabular}


Prevalence of parasitaemia by microscopy

The prevalence of $P$. falciparum parasite carriage among various characteristic groups is shown in Table 1. The microscopy-based prevalence of asexual P. falciparum parasites was $2.7 \%(3 / 111)$ among females and $7.1 \%(7 / 98)$ in males with an overall prevalence of $4.8 \%$ $(10 / 209)$.

All the parasites were identified as P. falciparum and the geometric mean parasitaemia was 732 parasites/ $\mu 1$ of blood (range $=40$ to 3,520 parasites $/ \mu 1$ ). The highest proportion of individuals with parasitaemia observed in the $<5$ years age group was $10.3 \%(3 / 29)$ and this decreased with an observed increase in age (Figure 1) although not statistically significant $\left(\chi^{2}=3.57 ; \mathrm{p}=0.058\right)$. Two individuals aged 38 years and 3 years carried gametocytes at gametocytemia rates of 240 and 720 parasites/ $\mu 1$ of blood respectively. These same individuals also had the highest asexual parasitaemia, being 1440 and 3520 parasites/ $\mu 1$ of blood.



Figure 1 Prevalence of $P$. falciparum asexual parasites by age groups

Prevalence of Plasmodium asexual and gametocyte stages by RT-PCR

Of the 209 samples used for the molecular detection of parasites, $13.9 \%$ (29/209) were positive for Plasmodium spp, thus the overall PCR-based prevalence of asymptomatics which was approximately threefold over microscopy. There was no significant difference between the proportions of male, $51.7 \%(15 / 29)$ and female, $48.3 \%(14 / 29)$ carriers of the parasites $\left(\chi^{2}=2.25\right.$; $\mathrm{p}>0.05)$. The highest prevalence of $P$. falciparum parasites was observed among the $5-24$ year age group while the lowest was among the age-group $>44$ (Figure 1). The trend for decreasing PCR observed parasitaemia with age was significant $\left(\chi^{2}=7.97 ; p=0.004\right)$
Of the asymptomatic infections detected by PCR, 66\% $(19 / 29)$ were sub-microscopic infections, thus an overall prevalence was $9.1 \%(19 / 209)$. Among males and females, sub-microscopic prevalence of infections were $8.2 \%(8 / 98)$ and $9.9 \%(11 / 111)$ respectively which were not significantly different $\left(\chi^{2}=0.1921, p>0.05\right)$. The proportion of individuals with sub-microscopic infections was lowest among children below 5 years $(3.4 \%, 1 / 29)$ and highest among the 15-24 years age group (18.4\%, 7/37).

The Pfs 25 rRNA transcript detection method identified eight individuals as having P. falciparum gametocytes, thus a gametocyte prevalence of $3.8 \%(8 / 209)$. Three of the individuals with gametocytes did not have detectable asexual parasitaemia by microscopy. Gametocyte prevalence was highest $(6.9 \%, 2 / 29)$ among children under 5years (Figure 2).

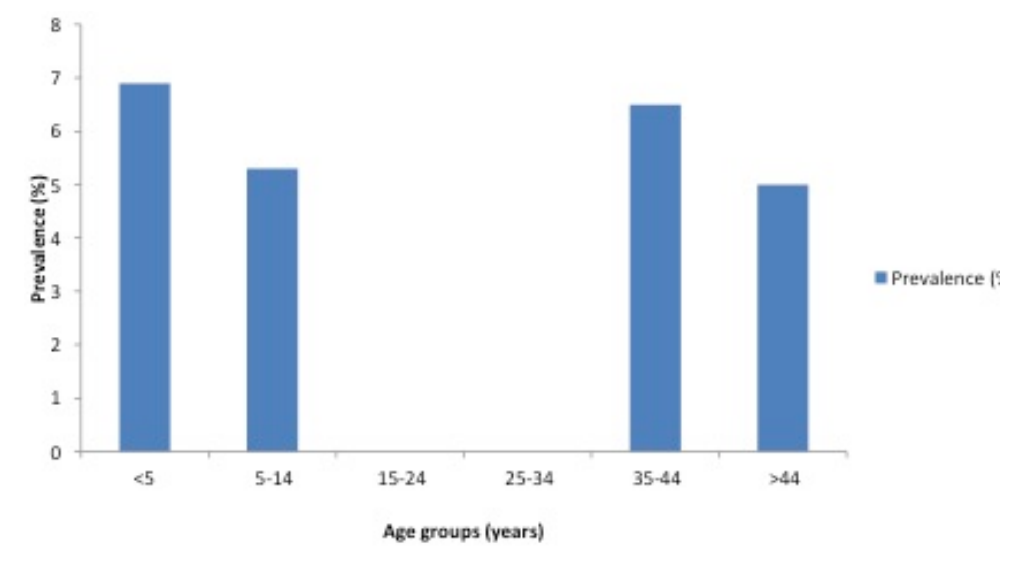

Figure 2 Prevalence of $P$. falciparum gametocytes by age groups

\section{DISCUSSION}

Our study determined the prevalence of submicroscopic asymptomatic infections in an area in northern Ghana during the dry season, a period when there is low to no transmission. ${ }^{16}$ Approximately $14 \%$ (29/209) of the study participants were asymptomatic $P$. falciparum carriers whilst $66 \%(19 / 29)$ of them were sub-microscopic infections with $4 \%(8 / 209)$ carrying gametocytes.

The presence of $P$. falciparum gametocytes in the human peripheral blood is an indicator of parasite transmission. ${ }^{26}$ Although the success of transmission increases as gametocyte density increases, transmission may still occur at low gametocyte densities. ${ }^{27}$ The low prevalence of $P$. falciparum gametocytes, $1 \%$ and $3.8 \%$ as detected by microscopy and PCR respectively, cannot therefore be underestimated as a major contributor to 
the next generation of transmission in the area. It is known that in areas of high malaria transmission intensity, gametocyte carriage is most prevalent in the younger age groups with high densities of asexual malaria parasites. ${ }^{28}$ which our study corroborates with our findings that the highest gametocytemia (6.9\%) was observed in children below 5 years. In addition, the two individuals with microscopic gametocytes also had the highest asexual parasitaemia which is consistent with the observation that high asexual parasitaemia results in high gametocytemia. ${ }^{7}$

The highest prevalence of $P$. falciparum infections detected by PCR was $22 \%$ in the 15-24 years age group, which could be as a result of protective immunity acquired over the years. This acquired immunity therefore keeps parasitaemia at very low levels. Since parasite density is controlled by acquired immunity in the infected host ${ }^{7}$ adults are more likely than children to carry sub-microscopic infections. ${ }^{29,30}$ Our study showed a higher prevalence of sub-microscopic infections among older children and adults ( $>5$ years) than among children $<5$ years $(10.3 \%$ versus $3.4 \%)$ which is expected. On the other hand, prevalence by microscopy was highest among children $<5$ years $(10.3 \%)$, an indication of higher parasite densities among the children who are still in the process of building up their protective immunity. For the effect of bednet use on carriage of asymptomatic infections, there was no significant difference between those who sleep under nets $(15.4 ; 4 / 26)$ and those who do not $(13.6 ; 25 / 183)(\mathrm{p}>0.05)$. This observation is quite interesting since one of the main interventions against malaria is the use of long lasting insecticide treated nets (LLINS).

The microscopic identification of $P$. falciparum parasites have been shown to miss on average about $50 \%$ of the infections in endemic areas compared to PCR. ${ }^{31}$ This study showed that PCR detected 13.9\% (29/209) against $4.8 \%(10 / 209)$ by microscopy which is indicative of the high sensitivity of detection by molecular methods. A study conducted in Colombia showed that molecular tools detected $61 \%$ more infections than microscopy. ${ }^{32}$ Therefore in line with the assessment of progress in reducing malaria transmission, PCR proves to be the best tool for estimating parasite prevalence in the general population for mass interventions. The implication of our findings is that there is an urgent need to detect sub-microscopic infections in this era when the global community is targeting malaria elimination. In the event of high prevalence of low density infections, the use of microscopy for the diagnosis of malaria will be limited. Ghana is still at the control stage and would need intensify efforts to reach the pre-elimination stage of the disease. ${ }^{33}$ Thus it is appropriate to use very sensitive diag- nostic tools in surveys aimed at establishing prevalence of malaria to inform choice of elimination strategies. Further studies are underway to detect asymptomatic infections in other parts of the north of Ghana with seasonal malaria transmission to accumulate more data to guide the National Malaria Control Programme in formulating future control and elimination strategies $s$ in Ghana.

In conclusion, the presence of sub-microscopic asexual stage and gametocytes in the dry season in Navrongo is indicative that persistent latent malaria infections occur and that these could supply the source of parasites for the next transmission season. The findings highlight the presence of sub-microscopic infections and therefore the need for active case detection during surveillance to eliminate "asymptomatic reservoir" parasites and consequently break the transmission of the disease to achieve malaria elimination in Ghana.

\section{ACKNOWLEDGEMENTS}

The authors wish to thank the malaria endemic communities of Navrongo in the Upper East Region of Ghana for willingly participating in this study. The Bill and Melinda Gates Foundation grant awarded to Noguchi Memorial Institute for Medical Research Postdoctoral and Postgraduate Training in Infectious Diseases Research (Global Health Grant \# OPP52155) funded the field work through a fellowship award to Master of Philosophy student, Mr. Geoffrey R. Atelu. Molecular analysis was funded by existing projects of Professor Michael D. Wilson (NIAID RO1 \# 1RO1AI099623) and Dr Nancy O. Duah, (EDCTP-WANETAM Project code CB.07.41700.007). The authors are grateful for the contributions made by Professor Neils Ben Quashie and Dr. Bismark Sarfo on the conduct of the field work. The assistance from laboratory staff, Miss Janice Tagoe, Miss Selassie Kumordzie, Mr John Mevemeo and $\mathrm{Mr}$ Elorm Akoto is appreciated. The authors want to thank the Director of NMIMR, Professor Kwadwo Koram, for his permission to publish the findings from this study.

\section{REFERENCES}

1. WHO: World Malaria Report 2014. www.who.int/malaria/publications/world_malaria_ report_2014/en/2014. Accessed 2 June 2015

2. Cotter C, Sturrock HJ, Hsiang MS, Liu J, Phillips AA, Hwang J, Gueye CS, Fullman N, Gosling RD, Feachem RG: The changing epidemiology of malaria elimination: new strategies for new challenges. Lancet 2013, 382(9895):900-911.

3. Mendis K, Rietveld A, Warsame M, Bosman A, Greenwood B, Wernsdorfer WH: From malaria 
control to eradication: The WHO perspective. Trop Med Int Health 2009, 14(7):802-809.

4. Sturrock HJ, Hsiang MS, Cohen JM, Smith DL, Greenhouse B, Bousema T, Gosling RD: Targeting asymptomatic malaria infections: active surveillance in control and elimination. PLoS Med 2013, 10(6):e1001467.

5. Guerin PJ, Olliaro P, Nosten F, Druilhe P, Laxminarayan R, Binka F, Kilama WL, Ford N, White NJ: Malaria: current status of control, diagnosis, treatment, and a proposed agenda for research and development. Lancet Infect Dis 2002, 2(9):564-573.

6. malERA: The Malaria Eradication Research Agenda. PLoS Medicine 2011, www.ploscollections.org/article/browseIssue.action ?issue=info:doi/10.1371/issue.pcol.v07.i13

Accessed 2 June 2015

7. Bousema T, Okell L, Felger I, Drakeley C: Asymptomatic malaria infections: detectability, transmissibility and public health relevance. Nat Rev Microbiol 2014, 12(12):833-840.

8. Day KP, Hayward RE, Dyer M: The biology of Plasmodium falciparum transmission stages. Parasitology 1998, 116 Suppl:S95-109.

9. Lin JT, Saunders DL, Meshnick SR: The role of submicroscopic parasitemia in malaria transmission: what is the evidence? Trends Parasitol 2014, 30(4):183-190.

10. Bousema T, Okell L, Shekalaghe S, Griffin JT, Omar S, Sawa P, Sutherland C, Sauerwein R, Ghani AC, Drakeley C: Revisiting the circulation time of Plasmodium falciparum gametocytes: molecular detection methods to estimate the duration of gametocyte carriage and the effect of gametocytocidal drugs. Malar J 2010, 9:136.

11. Bousema JT, Gouagna LC, Drakeley CJ, Meutstege AM, Okech BA, Akim IN, Beier JC, Githure JI, Sauerwein RW: Plasmodium falciparum gametocyte carriage in asymptomatic children in western Kenya. Malar J 2004, 3:18.

12. Dunyo S, Milligan P, Edwards T, Sutherland C, Targett G, Pinder M: Gametocytaemia after drug treatment of asymptomatic Plasmodium falciparum. PLoS Clin Trials 2006, 1(4):e20.

13. Golassa L, Enweji N, Erko B, Aseffa A, Swedberg G: Detection of a substantial number of submicroscopic Plasmodium falciparum infections by polymerase chain reaction: a potential threat to malaria control and diagnosis in Ethiopia. Malar Journal 2013, 12:352.

14. Cucunuba ZM, Guerra A, Rivera JA, Nicholls RS: Comparison of asymptomatic Plasmodium spp. infection in two malaria-endemic Colombian locations. Transactions of the $R$ Soc Trop Med Hyg 2013, 107(2):129-136.
15. Diallo A, Ndam NT, Moussiliou A, Dos Santos S, Ndonky A, Borderon M, Oliveau S, Lalou R, Le Hesran JY: Asymptomatic carriage of plasmodium in urban Dakar: the risk of malaria should not be underestimated. PloS One 2012, 7(2):e31100.

16. Price R, Nosten F, Simpson JA, Luxemburger C, Phaipun L, ter Kuile F, van Vugt M, Chongsuphajaisiddhi T, White NJ: Risk factors for gametocyte carriage in uncomplicated falciparum malaria. Am J Trop Med Hyg 1999, 60(6):1019-1023.

17. WHO: World Malaria Report. www.who.int/malaria/publications/world_malaria_ report_2013/en/2013. Accessed 2 June 2015

18. Kasasa S, Asoala V, Gosoniu L, Anto F, Adjuik M, Tindana C, Smith T, Owusu-Agyei S, Vounatsou P: Spatio-temporal malaria transmission patterns in Navrongo demographic surveillance site, northern Ghana. Malar J 2013, 12:63.

19. Oduro AR, Wak G, Azongo D, Debpuur C, Wontuo P, Kondayire F, Welaga P, Bawah A, Nazzar A, Williams J et al: Profile of the Navrongo Health and Demographic Surveillance System. Int J Epidemiol 2012, 41(4):968-976.

20. Appawu M, Owusu-Agyei S, Dadzie S, Asoala V, Anto F, Koram K, Rogers W, Nkrumah F, Hoffman SL, Fryauff DJ: Malaria transmission dynamics at a site in northern Ghana proposed for testing malaria vaccines. Trop Med \& Int Health 2004, 9(1):164170 .

21. Kamau E, Tolbert LS, Kortepeter L, Pratt M, Nyakoe N, Muringo L, Ogutu B, Waitumbi JN, Ockenhouse CF: Development of a highly sensitive genus-specific quantitative reverse transcriptase real-time PCR assay for detection and quantitation of plasmodium by amplifying RNA and DNA of the 18S rRNA genes. J Clin Microbiol 2011, 49(8):2946-2953.

22. Jones S, Sutherland CJ, Hermsen C, Arens T, Teelen K, Hallett R, Corran P, van der VegteBolmer M, Sauerwein R, Drakeley CJ et al: Filter paper collection of Plasmodium falciparum mRNA for detecting low-density gametocytes. Malar $J$ 2012, 11:266.

23. Wampfler R, Mwingira F, Javati S, Robinson L, Betuela I, Siba P, Beck HP, Mueller I, Felger I: Strategies for detection of Plasmodium species gametocytes. PloS One 2013, 8(9):e76316.

24. Nsobya SL, Parikh S, Kironde F, Lubega G, Kamya MR, Rosenthal PJ, Dorsey G: Molecular evaluation of natural history of asymptomatic parasitemia in ugandan children. J Infect Dis 2004, 189(12):22202226.

25. Snounou G, Viriyakosol S, Zhu XP, Jarra W, Pinheiro L, do Rosario VE, Thaithong S, Brown KN: High sensitivity of detection of human malaria par- 
asites by the use of nested polymerase chain reaction. Mol Biochem Parasitol 1993, 61(2):315-320.

26. Ouedraogo AL, Bousema T, Schneider P, de Vlas SJ, Ilboudo-Sanogo E, Cuzin-Ouattara N, Nebie I, Roeffen W, Verhave JP, Luty AJ et al: Substantial contribution of submicroscopical Plasmodium falciparum gametocyte carriage to the infectious reservoir in an area of seasonal transmission. PloS One 2009, 4(12):e8410.

27. Churcher TS, Bousema T, Walker M, Drakeley C, Schneider P, Ouedraogo AL, Basanez MG: Predicting mosquito infection from Plasmodium falciparum gametocyte density and estimating the reservoir of infection. Elife 2013, 2:e00626.

28. Bousema T, Drakeley C: Epidemiology and infectivity of Plasmodium falciparum and Plasmodium vivax gametocytes in relation to malaria control and elimination. Clin Microbiol Rev 2011, 24(2):377410.

29. West PA, Protopopoff N, Rowland M, Cumming E, Rand A, Drakeley C, Wright A, Kivaju Z, Kirby $\mathrm{MJ}$, Mosha FW et al: Malaria risk factors in North
West Tanzania: the effect of spraying, nets and wealth. PLoS One 2013, 8(6): e65787.

30. Okell LC, Bousema T, Griffin JT, Ouedraogo AL, Ghani AC, Drakeley CJ: Factors determining the occurrence of submicroscopic malaria infections and their relevance for control. Nat Commun 2012, $3: 1237$.

31. da Silva-Nunes M, Moreno M, Conn JE, Gamboa D, Abeles S, Vinetz JM, Ferreira MU: Amazonian malaria: asymptomatic human reservoirs, diagnostic challenges, environmentally driven changes in mosquito vector populations, and the mandate for sustainable control strategies. Acta Trop 2012, 121(3):281-291.

32. Cucunuba ZM, Guerra AP, Rivera JA, Noicholls RB: Comparison of asymptomatic Plasmodium spp. infection in two malaria-endemic Colombian locations. Transactions of the $R$ Soc Trop Med Hyg 2012, 107(2).

33. GDHS: Ghana Demographic and Health Survey Key Indicators. www.statsghana.gov.gh/publications 2014.Accessed 2 June 2015 